\title{
Concerns of Teachers about the Implementation of Information and Communication Technology Curriculum in Basic Education in Ghana
}

\author{
Frederick Kwaku Sarfo \\ University of Education, Ghana \\ Francis Amankwah \\ University of Education, Ghana \\ Stephen Baafi-Frimpong \\ University of Cape Coast, Ghana \\ Joseph Asomani \\ University of Education, Ghana
}

\begin{abstract}
Research findings in the literature show that teachers' concern about change process is extremely personal and it influences the implementation of innovation. This study aimed at assessing information and communication technology teachers' stages of concern regarding the implementation of information and communication technology (ICT) curriculum in basic schools. It also examined the effects of teachers' personal factors or variables such as gender and teaching experience on their stages of concern towards the implementation of ICT curriculum. Modified Stages of Concerns Questionnaires (SoCQ) (Hall, George \& Rutherford 1979) based on Concern Based Adoption Model (CBAM) were used to collect data from 346 respondents. Data collected were analyzed using both descriptive and inferential statistics. The result of the study showed that teachers generally had their first and second high concerns at informational and consequence stages respectively and with low concern at awareness stage. Furthermore, statistically significant difference was found between gender and informational, management, consequence, collaboration and refocusing concerns. However, according to the results, teachers' stages of concerns were not related to their teaching experience.
\end{abstract}

Keywords: Information and communication technology, Curriculum implementation, Basic education, Teacher concerns

\section{Introduction}

Many international thought leaders and business leaders are increasingly asking educational systems to equip students with $21^{\text {st }}$ century competencies that will enable students to face complex challenges of the current century and in the future (Ontario, 2016). Schools in knowledge societies have to cultivate these qualities or competencies in young people for their nations to survive and stay competitive (Kanu \& Glor, 2006). According to Ontario (2016), international organizations such as "Organization for Economic Cooperation and Development (OECD), the European Commission, the Partnership for $21^{\text {st }}$ Century Skills (P21), and the US 
National Research Council have brought rigor to the research and intellectual debate regarding 21st century competencies" (p. 10). All these organizations recognized information and communication technology (ICT) skills (or computer literacy) as one of the important components of $21^{\text {st }}$ century competencies. Grimus (2000) argued that the relevance of teaching and studying of ICT in schools, especially at the basic school levels cannot be overemphasized as it prepares learners to cope with the demands of the current century. To support this argument, the United Nations Educational, Scientific, and Cultural Organizations (UNESCO) (2002) asserts that ICT has the ability to change the nature of learning, as well as the role of teachers and students in the teaching and learning process.

With regard to the above conception, there is a growing demand on countries and educational institutions to teach ICT skills and knowledge that students need for the $21^{\text {st }}$ century challenges. For instance, in developing ICT literacy among its citizenry, government of Ghana, through the Ministry of Education (MoE) developed ICT in Education Policy to ensure that the Ghanaian education sector provides adequate opportunities for Ghanaian students to cope with the demands of the 21 st century.

According to MoE (2008), the policy was influenced by a number of factors, including:

1. World Forum on Education, Dakar (2000)

2. Report of Educational Reforms in Ghana: Meeting Challenges in the 21st Century (2002)

3. ICT in Education Policy Framework: which highlights key issues and expected benefits of ICTs in Education (2002)

4. The Ghana ICT for Accelerated Development (ICT4AD) Policy (2003) recognizes education as a cross-cutting issue within the national framework crucial to the support of the thirteen other national pillars.

5. Ghana Education Strategic Plan 2003 - 2015: Volumes I and II (2003)

6. White Paper on the Report of the Education Reform Review Committee (2004)

The overall goal of the policy according to Ministry of Education (2008), "is to enable students from Ghanaian educational institutions (formal and non-formal) to confidently and creatively use ICT tools and resources to develop requisite skills and knowledge needed to be active participants in the global knowledge economy" (p. 13).

To fulfil the realization of the policy, in the year 2007, ICT curricula were introduced in all basic and second cycle schools in rural and urban areas of Ghana. This is in line with the assertion by Oliver (1965) that "curriculum obsolesce occurs at a rapid rate as educational programmes face new demands for intellectual quality amid startling expansions in knowledge" (p. 1). Stenhouse, (1975) who elucidated the effect of new curriculum, argued that "genuine innovation begets incompetence. It deskills teachers and pupils alike, suppressing acquired competencies and demanding the development of new ones" (p. 170). This indicates that once a new curriculum is introduced, teachers have to do new things in new ways.

The difficulty and complexity of the implementation of new curriculum by teachers have been noted all over the world (Fullan, 1997; 2001). This supports the argument by Hargreaves (as cited in Kunu \& Glor, 2006) that teaching in the current century is increasing complex work where teachers find themselves caught in "a triangle of interests and imperatives" (p. 101). The demands and pressures associated with new curriculum implementation especially ICT call for 
change in teachers (Fullan, 1997; Hall \& Hord, 2006). The change process in teachers is extremely personal experience and how it is perceived by the individual teachers (who are the main ICT curriculum implementers in this regard) strongly influences the implementation. Teachers raise a lot of issues and concerns during the change process. Identifying and addressing teachers concerns during change is critical for successful implementation of any innovation (Hall \& Hord, 2001). From the point of view that teachers are resistant to change as indicated by Fullan (2001), systematic assessment on teachers' stages of concern in the process of implementing ICT curriculum is of critical importance. Consistent research findings from the literature (e.g., Anderson, 1997; Wang, 2014; Gokcek \& Baki; 2013; Hall \& Hord, 2001) show that Change Model such as Concern Based Adoption Model (CBAM) is effective for identifying and addressing issues and concerns of teachers when they are implementing innovation such as ICT curriculum, as well as to promote their professional development. However most of these research studies that employed CBAM to identify teachers issues of concern during implementation are focused on other disciplines such as Mathematics (e.g., Cetinkaya, 2012; Gokcek \& Baki, 2013,), English (e.g, Wang, 2014), Accounting (Kwarteng, 2009); others (e.g, Dubey \& Alam, 2014) focused on teachers' concern in ICT education at the tertiary level. More specifically little is known about the use of CBAM to identify and address teachers' concern in implementing ICT curriculum at the basic education. On the basis of this deficiency in the literature, this study was designed to apply CBAM stages of concerns to identify the concern of basic school teachers in the implementation of ICT curriculum at the basic level. The study was also designed to assess teachers' gender and teaching experience and their concerns about the implementation of the ICT curriculum.

\section{Literature Review}

This study was designed within the framework of the concerns-based adoption model (CBAM) (Hall, Wallace \& Dossett, 1973). The CBAM which was developed from Fuller's (1969) concern theory of teacher development, is a theoretical model for identifying the concerns of individuals during the implementation of educational or curriculum change. The CBAM is guided by the following assumptions: (1) change is a process; (2) change is individual; (3) the perceptions and feelings of individuals are crucial to successful implementation; (4) individuals proceed through stages in their feelings about perceptions of, and level of skill in the use of an innovation; and (5) change facilitators must proceed systematically, assess regularly, and provide support continually (Marsh \& Willis, 2007). According to Anderson (1997), CBAM is a methodology for measurement, description and explanation of different aspects of the implementation of curricular and instructional innovation. He further described the model as "the most robust and empirically grounded theoretical model for the implementation of educational innovations to come out of educational change research in the 1970s and 1980s" (p.331).

The CBAM is a complex multi-dimensional framework and it comprises the stages of concern (SoC), levels of use, and innovation configuration. Hall, George and Rutherford (1979) defined concern as "the composite representation of the feelings, preoccupation, thought and consideration given to a particular issue or task" (p. 5). Van den Berg and Ros (1999) explained concern as "the questions, uncertainties, and possible resistance that teachers may have in response to new situations and/or changing demands" (p.880). Stages of Concern component of CBAM assess the various concerns teachers express in the process of implementing curriculum. Hall et al. (1979) conceptualized that teacher concern regarding curriculum implementation is a developmental construct, consisting of a total of seven sequential stages: 
awareness stage, informational stage, personal stage, management stage, consequence stage, collaboration stage, and refocusing stage.

At the awareness stage teachers have inadequate knowledge about the nature of the innovation or the new curriculum and they are concerned about what the innovation or new curriculum is. At the informational stage teachers express concern about the requirements of the innovation and how it works. At the personal stage teachers express concern about how the innovation affects them personally and their plans to do it. At the management stage teachers express concern on the processes and tasks related to efficiency, organization, management, scheduling and time demands to implement the innovation. At the consequence stage teachers express concern on the impact of the innovation on students within the teacher's sphere of control. Particular attention is centered on relevance of the innovation for students. At the collaboration stage teachers' concern is focused on the coordination and cooperation with others on the use of the innovation. Finally, at the refocusing stage teachers' concern is centered on something else that they can do to help the innovation better (Cheung \& Ng, 2000; Hall \& Hord, 2006)

According to Hall et al. (1979), every teacher's concern about curriculum implementation progresses through these seven SoC. Teachers can experience several SoC concurrently, but at different degrees of intensity. Thus, teachers progress from self-oriented concerns (awareness, informational, personal stages) through task-oriented (e.g., stage 3) to impact-oriented concerns (e.g., stages 4, 5, and 6). According to Hord (1990), even though each of the stages is distinct, they are not mutually exclusive.

Initiating, implementing, and sustaining change in educational context are complex tasks (Fullan, 2007) and have not been easy. When teachers are overwhelmed, feel uncertain and unsuccessful during implementation of new curriculum (e.g., ICT curriculum in Ghana) their concerns will concentrate at the lower levels and would not be ready to grow. If their concerns or professional development needs are not identified and addressed they may remain and become stuck at the lower levels for the rest of their career, and ultimately make the successful implementation of the innovation impossible. Identifying their concerns at each stage and addressing them will help them continue to develop over time till they get to the highest level which guarantees successful implementation of innovation or curriculum. CBAM stages of concern model is tested and effective research model employed to identify and address teachers' concerns and questions before and during implementation of innovation (Hall \& Hord, 2001; Hall et al., 1979; Hossain, 2000). So many researchers have employed CBAM to assess teachers' concerns on implementing different kinds of innovation/curriculum (Hall \& Hord, 2001). Consequently the application of CBAM stages of concerns is gaining more interest and attention in this era of change. The SoC component, which is the basis for this study, tracks the feelings, questions, uncertainties, and resistance that basic school teachers may have in (response to ) or as they are involved in the implementation of ICT curriculum since 2007.

\section{Teacher Concerns about Implementation of ICT Curriculum}

The importance of helping students to develop ICT functional skills and ICT skills for learning and to cope with the requirements in the $21^{\text {st }}$ century has compelled governments, educational leaders and innovators both in developed and developing countries to plan and implement ICT curriculum at all levels and areas of education. This has further compelled educational (technology/change) researchers to employ CBAM stages of concern to investigate the factors that influence successful implementation of ICT curriculum in education, as well as the concerns 
or feelings of teachers during the change process. For instance, Alshammari (2000) employed CBAM stages of concern to examine the developmental stages of concern of 312 intermediate school teachers toward implementation of information technology curriculum in Kuwait. The results revealed that teachers had first and second high concerns related to collaboration and personal stages respectively. Teachers also reported low concerns at the management and awareness stages. Roxie (2005) also used CBAM stages of concern to investigate public high school teachers' concern regarding the implementation of the phase three software program CLASSROOM xp, InterGrade Pro and Blackboard 5.5. Results indicated that teachers had three high concerns related to awareness, personal and management. Similarly, In Cyprus, Chrysostomou and Mousoulides (2009) employed CBAM stages of concern to conduct a research study on elementary mathematics teachers' concerns and beliefs about the implementation of ICT in mathematics curriculum. The results revealed the existence of teachers' concerns about 1) the nature of the curriculum, 2) the consequences on the organization of teaching, and 3) the effectiveness of the curriculum. In measuring the concerns of ICT education, Dubey and Alam (2014) found out from their research study that pre-service students had high concerns at informational stage and very low concerns at consequence, collaboration and refocusing stages about.

In Ghana, CBAM stages of concern have been used to assess teachers concern of implementation of some innovations but the attention has not been focused on implementation of ICT curriculum in the basic schools. For instance, in a research study, Cobbold and Ani-Boi (2011) adapted and used CBAM stages of concern questionnaires to gather data from 316 primary school teachers about their concerns on the implementation of 2007 educational reform. The results indicated that teachers had high personal and management concerns, and low informational concerns. Again, using CBAM stages of concern, Kwarteng (2009) assessed accounting teachers' concerns about status of accounting curriculum implementation. The findings of the study showed that accounting teachers at second cycle schools had their first and second high concerns at awareness and personal stages respectively with low concern at refocusing stage. In addition, Acquah (2012) conducted a research study to examine the status of implementation of the ICT curriculum in Ghanaian basic schools. The results of the study, among other things, showed that teachers have positive perception towards the teaching of ICT in primary schools. It is important to note that Acquah did not apply the CBAM in his study.

\section{Gender and Teachers' Concerns about the Implementation of ICT curriculum}

Gender has been identified as one of the variables that can affect successful implementation of ICT curriculum in schools. Past research studies (e.g., Cunningham, 2007) from science, technology, engineering and mathematics (STEM) provide theoretical basis for the study of gender and implementation ICT of curriculum. However, generally, the previous studies in the literature on the effect of teachers' gender on the successful implementation of ICT in education are not conclusive. More specifically, it seems similar findings are reported in research studies on CBAM stages of concerns and implementation of ICT curriculum. For instance, Hawes (1993) explored the concerns of the Keene State College faculty members about the implementation of a microcomputer network. The study found that no significant relationship existed between teachers' stages of concern and gender. In addition, AL-Rawajfih, Fong and Idros (2010) examined teachers' stages of concerns in Jordan Discovery Schools on implementation of elearning into education. A total of 350 teachers were used for the study. The findings from the study, among others, indicated that male and female teachers did not show any difference in any of the categories of concerns. Roxie's (2005) research study also among others, considered 
difference in teacher concerns and gender. The ANOVA test result showed no significant difference between teacher concerns and gender. In contrast, in studying the developmental stages of concern of 312 teachers toward implementation of the Information Technology curriculum in Kuwait, Alshammari (2000) found that females had high concerns at the collaboration and informational stages, with low concern related to awareness. The study also reported a significant difference between male and female at management and refocusing stages.

\section{Teaching Experience and Concerns about the Implementation of ICT Curriculum}

In cognitive psychology, consistent research findings by Ericsson, Krampe and Tesch-Romer (1993) indicated that essential features of experts' superior performance are acquired through experience and that the effect of practice on performance is something which cannot be contested. Following this line of argument, it is assumed that an extended period of teachers' teaching experience would have positive effects on his teaching activities or implementation of curriculum. Interestingly, generally, in the contexts of implementation of ICT in education, it seems this is not the case and the situation is not very clear (Buabeng-Andoh, 2012).For instance, research study conducted by Russel, Bebell, Dwyer, and Connor (2003) revealed that teachers with five or less years of teaching experience were significantly more capable and confident in using computers and technology in teaching than teachers who had had more than six years teaching experience. In addition, the results of research study conducted by Chrysostomou and Mousoulides (2009) indicate that there is no significant difference between teachers' experiences and their concerns about management and consequence stages of implementation of ICT mathematics curriculum. Interestingly, other researchers found significant differences between teachers' stages of concerns and their years of teaching experience (Cheung \& Ng, 2000; Lau \& Shiu, 2008).

\section{Research Questions and Research Model}

From the previous studies reviewed, it is understood that, specifically, there is dearth of research studies that employed CBAM to investigate into basic school teachers' concerns about the implementation of ICT curriculum. For instance in Ghana, some researchers (e.g., Cobbold \& AniBoi, 2011; Kwarteng, 2009) have employed CBAM to identify the concerns of teachers in implementing some new curricula. However, little is known about the use of CBAM to identify and address teachers' concern in implementing ICT curriculum at the basic education level since it was introduced in 2007. It is also evident from the review of the literature that research findings on the effect of teachers' gender and years of experience on their concerns of various stages about the implementation of ICT curriculum are not conclusive. This suggests that the influence of ICT teachers' gender and years of teaching experience as teacher related variables on their stages of concerns about the implementation of ICT curriculum in the basic schools need further research investigation for better clarification. To fill these identified research gaps in the literature and also to contribute to the successful implementation of ICT curriculum in the basic schools the present study was designed to answer the following research questions:

1. What are the teachers' concerns about the implementation of ICT curriculum in the basic schools?

2. Are there any significant differences between male and female basic school teachers' stages of concerns about the implementation of ICT curriculum? 
3. Are there any significant differences between experienced and inexperienced basic school teachers' stages of concerns about the implementation of ICT curriculum?

The variables that have been taken into consideration and the relationships that have been discussed in this study are presented in the model in figure 1.

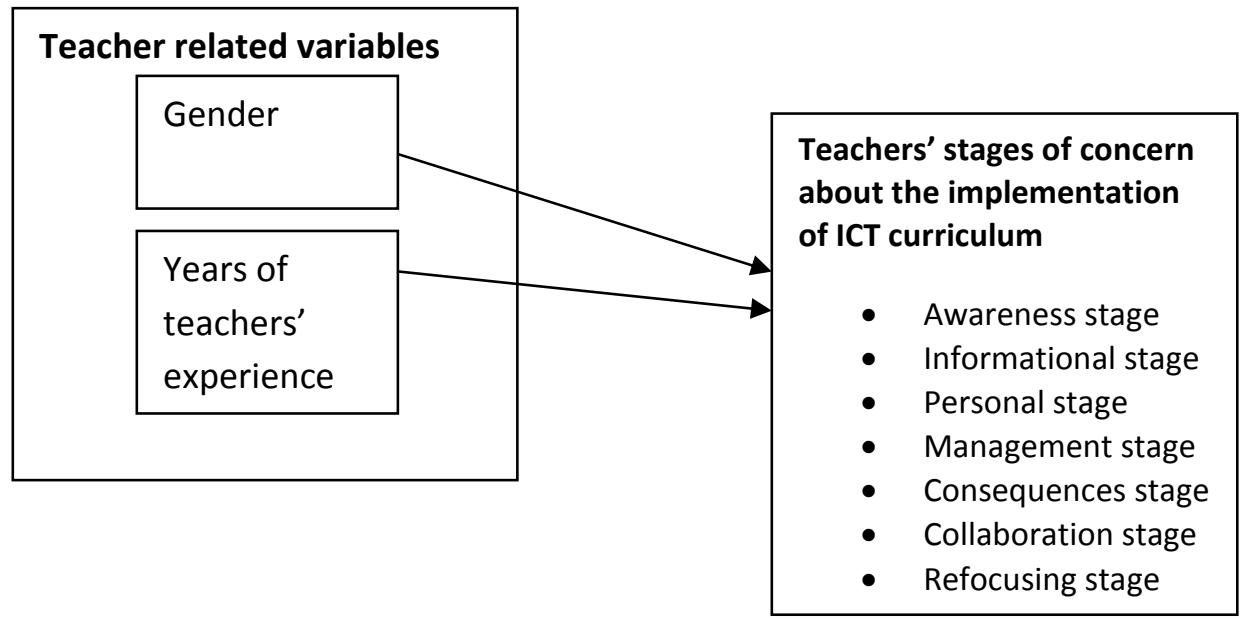

Figure 1. The Research Model

\section{Methodology}

\section{Participants}

The target population for the study was 1390 public and private basic school teachers (males and females) in the Kumasi metropolis of Ashanti Region, Ghana who are implementing the ICT curriculum. Based on the teachers' population of 1390, appropriate sample size of 302 was determined using Krejcie and Morgan (1970) table. However, in order to collect data of high quality that reflects majority of teachers implementing ICT curriculum in the basic schools, research participants of 360 were selected using stratified random sampling technique.

The participants of 360 (but 346 participants finally returned their questionnaires) were selected using stratified random sampling technique. The basic schools in the Kumasi metropolis were zoned into nine based on the nine sub metros (Bantama, Suame, Oforikrom, Manhyia, Tafo, Asokwa, Nhyiaeso, Subin and Kwadaso). This technique was not only helpful in making assessment of teachers concerns, but also enabled the researchers to generalize research findings in terms of the target population. Majority of the respondents 198 (57.2\%) had 1- 5 years of teaching experience whereas the remaining $148(42.8 \%)$ had more than 5 years of teaching experience. Male and female respondents were 181 (52.3\%) and 165(47.7\%) respectively. The average age of the respondents was 36.8 . The sample selected possessed the following characteristics (1) each individual had implement the ICT curriculum for at least one academic year, (2) the sample included male and female teachers and (3) the sample was drawn from both public and private basic schools. 


\section{Instrumentation}

The data collection instrument was a 35-item survey questionnaire which was adapted from the SoCQ (Hall et al. 1979) to ascertain the teachers' concerns toward the implementation of ICT curriculum in basic schools. The questionnaire was in two sections: A and B. Section A sought background information on the respondents like gender, age, teaching experience and school type. The section B part of the questionnaire consisted of 35 structured items on teachers' concerns with respect to the implementation of ICT curriculum. These teachers' concerns were classified into seven categories or subscales: Awareness (e.g. I am completely occupied with other things); Information (e.g. I have limited knowledge about the ICT curriculum); Personal (e.g. I am interested in knowing the effects of ICT curriculum on my professional status); Management (e.g. I am concerned about my inability to manage all the requirements of ICT curriculum); Consequence (I am concerned about how the ICT curriculum affects students); Collaboration (e.g. I am interested in helping other teachers learn how to implement ICT curriculum); and Refocusing (e.g. I am concerned about revising my approach of using the ICT curriculum) and each category had five items each. The 35-items were measured on four point Likert scale ranging from Very true of me now $=4$, Somewhat true of me now $=3$, Not true of me now $=2$, to Irrelevant $=1$. The mean was calculated by summing up all the five items for each subscale. High number indicated high level of concern whilst low number indicated low level of concern. To ensure the validity of the items, the instrument was vetted by two experts in research methodology, measurement and evaluation who checked for appropriateness, ordering and clarity of the items. As a measure of reliability, the instrument was pre-tested on 40 ICT teachers at the basic school who were not part of the actual sample used in this study. A Cronbach's alpha reliability co-efficient of 0.86 was obtained from the pilot-study. The instrument therefore, was deemed appropriate for the study based on the suggestion of Fraenkel and Wallen (2000) that a reliability coefficient of 0.70 or above is high for research purposes and was used as such.

\section{Procedure for Data Collection}

In the administration of the questionnaires to the respondents, the researchers first sought permission from the Metropolitan Education Directorate and school heads that ensured smooth and problem free during the administration of the questionnaires. Thereafter, the researchers personally administered questionnaires to the respondents in their respective schools after respondents were briefed on how the questionnaires should be filled. Moreover, the respondents were assured of confidentiality of the responses they would give. The presence of the researchers in the respondents' schools offered opportunity for the researchers to clarify and assist the respondents on any problems they might face in responding to the items. After a period of one week, the completed questionnaires were retrieved from the respondents. Out of the 360 questionnaires administered, 346 were duly completed and returned indicating $96.1 \%$ return rate.

\section{Data Analysis Procedure}

The data were processed using SPSS 16.0 version. Descriptive statistics was used to answer research question 1 . Independent $t$ tests were carried out to answer research question 2 and 3. The dependent variables for the two research questions ( $2 \& 3$ ) were teachers' stages of concern 
and the independent variable for research question 2 was teachers' gender whilst teachers' teaching experience was the independent variable for research question 3.

\section{Results}

\section{Concerns of Teachers about the Implementation of ICT Curriculum}

Figure 1 shows levels of concerns of all basic school teachers who participated in the study about the implementation of ICT curriculum. This was calculated as the mean responses to each scale starting from Awareness stage to Refocusing stage. As recorded in Figure 1, the most intense concern stages were the Consequence $(M=10.60)$ and Informational $(M=10.15)$. On the contrary, teachers reported least concern at the Awareness stage $(M=8.18)$.

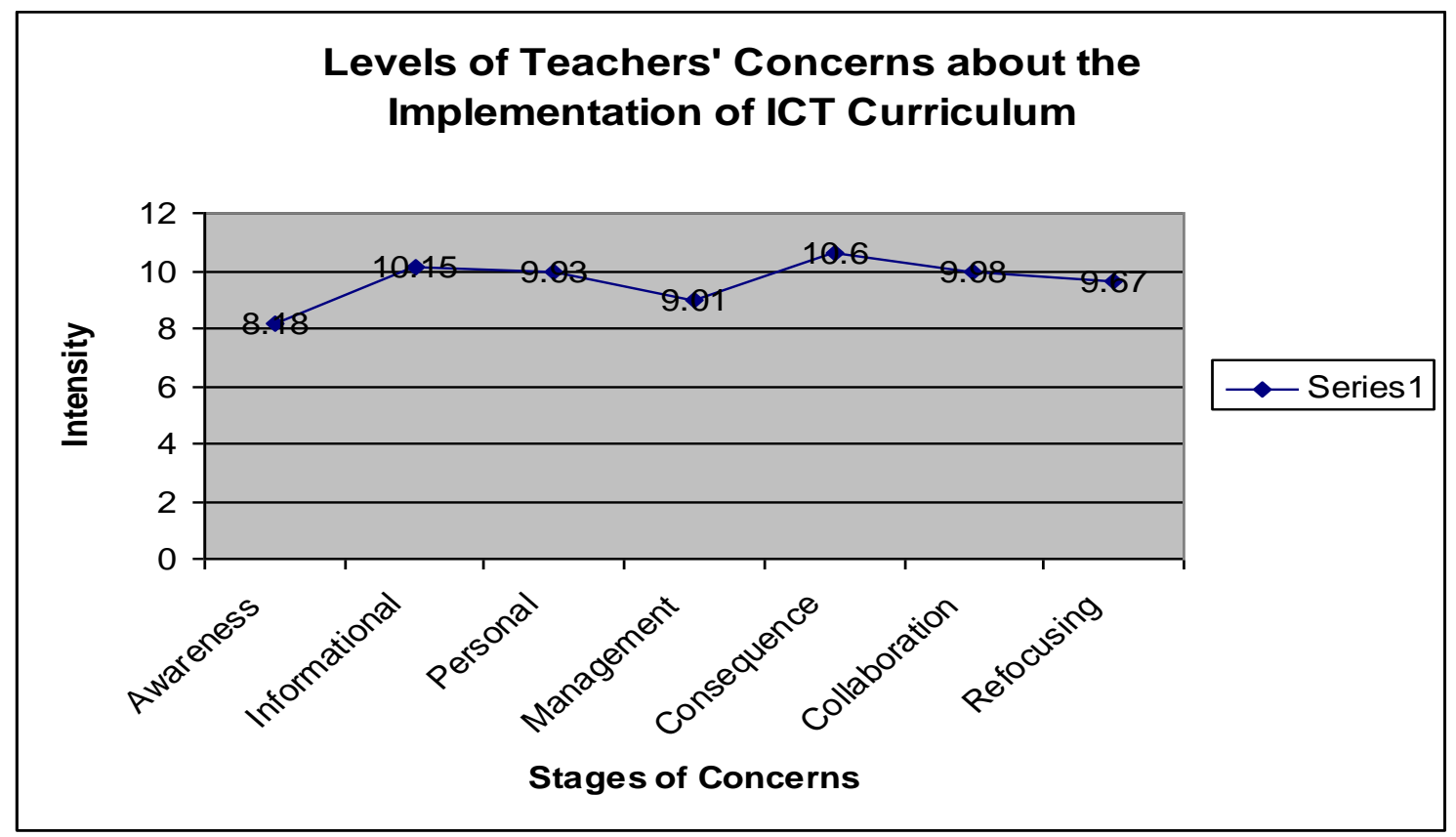

Figure 2. Levels of Teachers' Concern about the Implementation of ICT Curriculum

\section{Gender Differences in Teachers' Stages of Concerns about the Implementation of ICT Curriculum}

An independent sample $t$-test was used to investigate if teachers' gender has influence on their general concerns, as well as various stages of concern about the implementation of ICT curriculum in the basic schools. Generally, the result of independent sample $t$-test revealed statistically significant difference $t(344)=-2.757, p=.006$ ) between the mean scores for females $(M=10.02, S D=2.10)$ and males $(M=9.33, S D=2.55)$; indicating that, female teachers expressed more concerns about the implementation of ICT curriculum at the basic level than male teachers. The magnitude of the difference in the means was very small (eta squared $=0.007$ ). More concretely, in terms of various stages of concerns towards the implementation of ICT curriculum, statistically significant differences between the mean scores of females and males were found in relation to: 1 ) their informational concerns ( $t(344)=-3.356, p=.001)$ revealing that females expressed more informational concern $(M=10.70)$ than the males $(M=9.61) ; 2)$ their 
management concerns $(t(344)=-2.331, p=.021)$ indicating that females expressed more management concern $(M=9.41)$ than males $(M=8.65) ; 3)$ their consequence concerns $(t(344)=$ $-2.948, p=.003)$ revealing that females expressed more consequence concern $(M=11.14)$ than males $(M=10.07)$; 4$)$ collaboration concerns $(t(344)=-2.117, p=.035)$ meaning that females expressed more collaboration concern $(M=10.23)$ than males $(M=9.53)$; and 5$)$ their refocusing concerns $(t(344)=-2.616, p=.009)$ indicating that females $(M=10.47)$ expressed more refocusing concern $(M=10.47)$ than males about the implementation of ICT curriculum in the basic schools. However, no significant differences were found between male and female teachers regarding their awareness concerns and personal concerns about the implementation of ICT curriculum in the basic schools. This indicates that male and female teachers had similar awareness and personal concerns regarding the implementation of the ICT curriculum. Table 1 highlights this.

Table 1. Summary of t-test for Teachers' Level of Concerns in Relation to Gender

\begin{tabular}{cccccccc}
\hline Gender & $\mathbf{N}$ & Concern & Mean & SD & df & $\mathbf{t}$ & $\mathbf{P}$ \\
\hline Male & 181 & & 8.34 & 3.11 & & & \\
Female & 165 & Awareness & 8.01 & 2.80 & & & \\
Total & 346 & & 8.18 & 2.96 & 344 & 1.054 & .293 \\
\hline Male & 181 & & 9.61 & 3.50 & & & \\
Female & 165 & Informational & 10.70 & 2.49 & & & \\
Total & 346 & & 10.16 & 3.00 & 344 & -3.356 & $.001^{*}$ \\
\hline Male & 181 & & 9.63 & 2.98 & & & \\
Female & 165 & Personal & 10.22 & 2.56 & & & \\
Total & 346 & & 9.93 & 2.77 & 344 & -1.945 & .053 \\
\hline Male & 181 & & 8.65 & 3.20 & & & \\
Female & 165 & Management & 9.41 & 2.82 & & & \\
Total & 346 & & 9.03 & 3.01 & 344 & -2.331 & $.021^{*}$ \\
\hline Male & 181 & & 10.07 & 3.53 & & & \\
Female & 165 & Consequence & 11.14 & 3.21 & & & \\
Total & 346 & & 10.61 & 3.37 & 344 & -2.948 & $.003^{*}$ \\
\hline Male & 181 & & 9.53 & 3.07 & & & \\
Female & 165 & Collaboration & 10.23 & 3.08 & & & \\
Total & 346 & & 9.88 & 3.08 & 344 & -2.117 & $.035^{*}$ \\
\hline Male & 181 & & 9.50 & 3.42 & & & \\
Female & 165 & Refocusing & 10.47 & 3.23 & & & \\
Total & 346 & & 9.99 & 3.33 & 344 & -2.616 & $.009^{*}$ \\
\hline Male & 181 & & 9.33 & 2.55 & & & \\
Female & 165 & Overall teachers' concern & 10.02 & 2.10 & & & \\
Total & 346 & & 9.68 & 2.33 & 344 & -2.757 & $.006^{*}$ \\
\hline * & & & & & &
\end{tabular}

* significant at 0.05 level

The Influence of Teaching Experience on Teachers' Concerns Regarding the ICT Curriculum Implementation

Generally, the independent sample $t$-test conducted showed that there was no statistically significant difference in mean scores for those teachers who have taught between 1- 5 years 
and those who have taught for 6 years and above. Moreover, in terms of the subscales, no significant differences were found between teachers who have taught between 1-5 years and those who have taught for 6 years and above with respect to their concerns regarding the implementation of ICT curriculum. Table 2 highlights this.

Table 2. Independent t-test for Teachers' Concerns in Relation to Their Teaching Experience

\begin{tabular}{|c|c|c|c|c|c|c|c|}
\hline Teaching experience & $\mathbf{N}$ & Concerns & Mean & SD & df & $t$ & $\mathbf{P}$ \\
\hline $1-5$ years & 198 & & 8.25 & 2.82 & & & \\
\hline 6 years and above & 148 & Awareness & 8.09 & 3.17 & & & \\
\hline Total & 346 & & 8.17 & 2.99 & 344 & .474 & .636 \\
\hline $1-5$ years & 198 & & 9.89 & 2.87 & & & \\
\hline 6 years and above & 148 & Informational & 9.94 & 2.71 & & & \\
\hline Total & 346 & & 9.92 & 2.79 & 344 & -.165 & .869 \\
\hline $1-5$ years & 198 & & 10.01 & 3.49 & & & \\
\hline 6 years and above & 148 & Personal & 9.90 & 3.42 & & & \\
\hline Total & 346 & & 9.96 & 3.46 & 344 & .297 & .767 \\
\hline $1-5$ years & 198 & & 9.19 & 2.92 & & & \\
\hline 6 years and above & 148 & Management & 8.78 & 3.20 & & & \\
\hline Total & 346 & & 8.99 & 3.06 & 344 & 1.241 & .216 \\
\hline $1-5$ years & 198 & & 10.53 & 3.36 & & & \\
\hline 6 years and above & 148 & Consequence & 10.65 & 3.51 & & & \\
\hline Total & 346 & & 10.59 & 3.44 & 344 & -.332 & .740 \\
\hline $1-5$ years & 198 & & 9.95 & 2.94 & & & \\
\hline 6 years and above & 148 & Collaboration & 9.75 & 2.28 & & & \\
\hline Total & 346 & & 9.85 & 2.61 & 344 & .594 & .553 \\
\hline $1-5$ years & 198 & & 10.01 & 3.49 & & & \\
\hline 6 years and above & 148 & Refocusing & 9.90 & 3.42 & & & \\
\hline Total & 346 & & 9.96 & 3.46 & 344 & .297 & .767 \\
\hline $1-5$ years & 198 & & 9.71 & 2.30 & & & \\
\hline 6 years and above & 148 & $\begin{array}{l}\text { Overall teachers' } \\
\text { concern }\end{array}$ & 9.60 & 2.47 & & & \\
\hline Total & 346 & & 9.66 & 2.39 & 344 & .438 & .662 \\
\hline
\end{tabular}

\section{Discussion}

This present study employed CBAM to track teachers' concerns about the implementation of ICT curriculum in the basic schools. The study was also set out to ascertain the influence of teachers' gender and their teaching experience on their concerns about the implementation of ICT curriculum. Stages of Concern Questionnaire (SoCQ) developed by Hall et al. (1979) was used to collect data from the respondents.

Results from the study revealed that teachers generally expressed first and second high concerns at informational and consequence stages respectively with least concern at awareness stage. The teachers having high concerns at informational and consequence stages indicate that they are more concerned about how the ICT curriculum works and its effects on their students. These findings are similar to Chrysostomou and Mousoulides (2009) finding that in Cyprus elementary school teachers expressed more concern at consequence stage about the 
implementation of ICT mathematics curriculum. However, these findings of the present study are not consistent with Alshammari's (2000) findings that Kuwait intermediate school teachers had first and second high concerns related to collaboration and personal stages towards the implementation of information technology curriculum in Kuwait. The present findings and that of of Chrysostomou and Mousoulides (2009), and Alshammari (2000) to some certain degree suggest that basic school teachers in different countries have different concerns about the implementation of ICT curriculum in the basic schools. This might derive from the point that basic school teachers from different countries receive different support during the implementation of ICT curriculum in the basic schools.

According to Van den Berg and Ros (1999), curriculum implementation might take from three to five years for teachers to move from self-concerns (like informational stage) to higher stages of concern such as refocusing stage. In line with this proposition, the current finding is quite worrying and problematic since ICT curriculum has been implemented in basic schools in Ghana for about nine years and still the teachers who teach the ICT curriculum have hazy understanding of the curriculum and not clear about what is required of them and the program's impact on students. These findings are very significant and required critical attention from educational policy-makers and technology innovators (in Ghana). The deficiencies might be attributed to the fact that most of the teachers teaching ICT at the basic levels in Ghana do not have the required expertise or degree in ICT Education.

On the other hand, teachers' expression of low concern at awareness stage implies that they have high interest in the implementation of the ICT curriculum and as such they are deeply involved in its implementation. The finding is consistent with the finding of Alshammari (2000) that teachers have low concern at the awareness stage. The result of the present study also supports the finding of Acquah (2012) that teachers have positive perception about the teaching of ICT in primary schools. The teachers' expression of low awareness concern may also be attributed to their participation in various ICT workshops organized by Ghana Education Service.

The results of the study further indicate that generally, female teachers have more concerns than male teachers about the implementation of ICT curriculum at the basic schools. More specifically similar findings were also found in informational, management, consequence, collaboration, and refocusing stages of concerns. Interestingly, the findings showed that gender has no influence on teachers' concerns at awareness and personal stages of concerns. These findings of female teachers' high level of concerns at various sub-scales support Alshammari's (2000) findings that females have higher concerns at the collaboration and informational stages towards the implementation of information technology curriculum in Kuwait than males. The findings of the present study together with others in the literature that females have higher concerns than males on the various stages of concerns about the implementation of ICT curriculum indicate that teachers' gender and the successful implementation of ICT curriculum still remain an important phenomenon to consider. The finding of the study that females and male teachers have similar awareness and personal concern about the implementation of ICT curriculum in the basic schools to some extent agrees with previous studies of Roxie (2005), ALRawajfih, et al. (2010) and Hawes (1993). The basic reason for the similarity of the awareness and personal concerns might be that as a result of various training workshops organized for ICT teachers as indicated earlier, the female teachers are becoming more knowledgeable about ICT and are willing to continue in the teaching of ICT as their male counterparts.

To respond to the third research question, the results of the study revealed that teachers' teaching experience does not influence their general concern, as well as their various stages of 
concerns (awareness, informational, personal, management, consequence, collaboration and refocusing) towards the implementation of ICT curriculum in the basic schools. Thus teachers with 1-5 years of teaching experience and those with 6 years and above teaching experience have similar concerns. These findings of the present study imply that teachers' years of teaching experience are totally independent of stages of teachers' concerns about the implementation of ICT curriculum. This finding confirms the finding of Chrysostomou and Mousoulides (2009) that teachers teaching experience has no effect on their concerns about the implementation of ICT curriculum.

\section{Conclusion}

The study revealed that generally teachers have high concerns at informational and consequence stages respectively with low awareness concerns. This therefore, implies that teachers lack requisite knowledge on the ICT curriculum that will enable them to implement it successfully. Again, they have impact-oriented questions which bothered on the effect of ICT curriculum on the basic school students, even though they are knowledgeable of its existence in the basic schools. On the other hand, the findings of the current study together with others such as Alshammari (2000), and Chrysostomou and Mousoulides (2009) imply that teachers in different countries might have different concerns towards the implementation of ICT curriculum in the basic schools. The results also showed differences of concerns of male and female teachers across various stages of concern towards the implementation of ICT curriculum at the basic level. This underscores the critical importance of gender as a factor to consider in CBAM stages of concern as a model of change (for ICT implementation at the basic schools). The study however, revealed that when considering teachers' stages of concerns towards the implementation of ICT curriculum, teachers' teaching experience seems not to be a significant factor to consider.

The study adopted a cross sectional descriptive survey which tracked concerns of teachers at a given time. Since implementation is a process and teachers' concerns change over time, further studies should include a longitudinal study to follow the changes in teachers' concerns over time. Also, the other two dimensions of the CBAM (levels of use and innovation configuration) should be included in further research. In addition, future study should increase the sample size and address the relationships between stages of concern and other variables such as teachers' age, qualifications, school type, professional training and the duration in implementing the ICT curriculum.

Based on the findings and conclusion, it is recommended that educational innovators (educational authorities, teacher educators, educational technologists, etc) should continuously apply CBAM to identify basic school teachers issues and concerns about the implementation of ICT curriculum. This would enable them plan and deliver rigorous training programs for the teachers to upgrade their knowledge and skills about the ICT curriculum, where necessary, so as to reduce their concerns. And this would ultimately enable them to grow professionally for effective implementation of ICT curriculum. The organizers and trainers should take into consideration the gender of trainees as gender to some great extent has effect on teachers' concerns. Moreover, continuous monitoring, mentoring, and support for ICT teachers are also recommended for effective implementation of ICT curriculum at the basic school level (in Ghana). The study contributes to the importance of CBAM stages of concerns in the successful implementation of ICT curriculum in the basic schools and also adds more and new insight (from 
Ghanaian perspective) to teacher-related variables that influence CBAM stages of concern towards implementation of innovation.

\section{References}

Acquah, B.Y.S. (2012). Status of implementation of the ICT curriculum in Ghanaian basic schools. Journal of Arts and Humanities, 1(3), 27-37.

Albrini, A. (2006). Teachers' attitudes toward information and technologies: The case of Syrian EFL teachers. Computer Education, 47(4), 373-398.

AL-Rawajfih, K., Fong, S. F., \& Idros, S. N. S. (2010). Stages of concern in integrating e-learning in discovery schools. Asian Social Science, 6(8), 54-63.

Alshammari, B. S. (2000). The developmental stages of concern of teachers toward the implementation of the information technology curriculum in Kuwait. Unpublished doctoral dissertation, University of North Texas.

Anderson, S. E. (1997). Understanding teacher change: Revisiting the concerns based adoption model. Curriculum Inquiry, 27(3), 331-367.

Buabeng-Andoh, C. (2012). Factors influencing teachers' adoption and integration of information and communication technology into teaching: A review of the literature. International Journal of Education and Development using Information and Communication Technology, 8(1), 136-155.

Cetinkaya, B. (2012). Understanding teachers in the midst of reform: Teachers' concerns about reformed sixth grade mathematics curriculum in Turkey. Eurasia Journal of Mathematics, Science and Technology, 8(3), 155-166.

Cheung, D. \& Ng, D. (2000). Teachers' stages of concern about the target-oriented curriculum. Educational Journal, 28(1), 226-237.

Chrysostomou, M., \& Mousoulides, N. (2009). Teachers' beliefs about the adoption of new technologies in the mathematics curriculum. Proceedings of CERME 6 (pp. 1270-1279). Lyon, France.

Cobbold, C., \& Ani-Boi, E. (2011). Primary school teachers' concerns about implementing the 2007 educational reform in Ghana: A study in the Cape Coast metropolis. International Journal of Basic Education, 1(1), 122-132.

Cunningham, C. (2007). Linking STEM and communication technology research: A research agenda for technology and gender equality. Paper presented at the annual meeting of NCA $93^{\text {rd }}$ Annual Convention, TBA, Chicago, IL.

Dubey, D. A. \& Alam, M. (2014). Developing Fiji: Measuring the concerns of pre-service students for ICT in education. European Scientific Journal, 1(28), 195-24

Ericsson, K. A., Krampe, R. T., \& Tesch-Romer, C. (1993). The role of deliberate practice in the acquisition of expert performance. Psychological Review, 100(3), 363 -406.

Fullan, M. (2007). The new meaning of educational change $\left(4^{\text {th }}\right.$ ed. $)$. New York: Teachers College Press.

Fuller, F. F. (1969). Concerns of teachers: A developmental conceptualisation. American Educational Research Journal, 6(2), 207 -226. 
Fraenkel, J. R. \& Wallen, N. E. (2000). How to design and evaluate research in education $\left(4^{\text {th }}\right.$ ed.). New York: McGraw- Hill.

Gokcek, T. \& Baki, A. (2013).Turkish mathematics teachers concerns about the curriculum reform in the first year of implementation. Eurasia Journal of Mathematics, Science and Technology Education, 9(2), 177-190.

Grimus, M. (2000). ICT and multimedia in the primary school. Paper presented the $16^{\text {th }}$ Conference on Educational Uses of Information and Communication Technologies. Beijing, China.

Hall, G. E., George, A. A., \& Rutherford, W. L. (1979). Measuring stages of concerns about the innovation: A manual for use of soc questionnaire. Austin, TX: Research and Development Center for Teacher Education, University of Texas.

Hall, G. E. \& Hord, S. M. (2001). Implementing change: Patterns, principles and potholes. Boston: Allyn and Bacon.

Hall, G. E. \&Hord, S. M. (2006). Improving change: Patterns, principles, and potholes ( $2^{\text {nd }}$ ed.). Boston, MA: Pearson.

Hall, G. E., Wallace, R. C., \&Dossett, W. A. (1973). A developmental conceptualization of the adoption process within educational institutions. Austin, TX: Research and Development Center for Teacher Education, University of Texas.

Hawes (1993). Academic computing from a technological innovation perspective: Faculty concerns (Unpublished doctoral dissertation). University of Massachusetts, USA.

Hord, S. M. (1990). Realising school improvement through understanding the change process. Southeast Educational Laboratory, 1(1), 1-4.

Hossain, S. (2000). Stakeholder identification and analysis in the adoption of IT in education. (Unpublished master's dissertation). Brunel University, Uxbridge, UK.

Kanu, Y. \& Glor, M. (2006). 'Currere' to the rescue? Teachers as 'amateur intellectuals' in a knowledge society. Journal of the Canadian Association for Curriculum Studies, 4(2), 101 $-122$.

Krejcie, R.V., \& Morgan, D.W (1970). Determining sample size for research activities. Educational and Psychological Measurement, 30, 607-610.

Kwarteng, J. T. (2009). Status of accounting curriculum implementation: A concerns-based adoption model assessment in Ashanti and Central regions (Unpublished MPhil thesis). University of Cape Coast.

Lau, J. \& Shiu, J. (2008). Teachers' perceptions of implementing innovation: The use of pair work in large-scale and assessment in Hong Kong. Retrieved on 4 November 2016 from at http://www.iaea2008.cambridgeassessment.org.uk/ca/digitalAssests/164801_Lau.pdf. Accessed on 23/03/2014.

Marsh, C. J. \& Willis, G. (2007). Curriculum: Alternative approaches, ongoing issues $\left(4^{\text {th }} e d\right)$. Upper saddle River, NJ: Prentice Hall.

Ministry of Education (2008). ICT in education policy. Accra: MOE.

Oliver, A. I. (1965). Curriculum improvement: A guide to problems, principles and procedures. New York: Dodd Mead Company. 
Ontario (2016). $21^{\text {st }}$ century competencies: Foundation document for discussion. USA: The Ontario Public Service.

Stenhouse, L. (1975). An introduction to curriculum research and development. London: Heinemann.

Roxie, V. (2005). Teacher concerns during implementation of instructional management tool in public high school. Teaching and Teacher Education, 26(3), 56-64.

UNESCO (2002). ICT in teacher education: A planning satisfaction with asynchronous teaching and guide. UNESCO, Division of Higher Education.

Van den Berg, R. \&Ros, A. (1999). The permanent importance of the subjective reality of teachers during educational innovation: A concerns-based approach. American Educational Research Journal, 36(4), 879-906.

Wang, W. (2014). Teachers' stages of concerns and levels of use of a curriculum innovation in China: A case study. International Journal of English Language Teaching, 1(1), 22-31.

Correspondence: Frederick Kwaku Sarfo, Associate Professor in Educational Technology and Dean of Faculty of Education and Communication Sciences, College of Technology Education Kumasi, University of Education, Winneba, Ghana 